\title{
An experimental investigation on the flow resistance over a porous gravel-bed surface and its non-porous counterpart
}

\author{
Christy Ushanth Navaratnam ${ }^{1, *}$, Jochen Aberle ${ }^{1,2}$, Jie Qin $^{3}$ and Pierre-Yves Henry ${ }^{1}$ \\ ${ }^{1}$ Department of Civil and Environmental Engineering, Norwegian University of Science and \\ Technology (NTNU), S.P.Andersens veg 5, 7491, Trondheim, Norway. \\ ${ }^{2}$ Leichtweiß-Institut für Wasserbau, Technische Universität Braunschweig, 38106, Braunschweig, \\ Germany. \\ ${ }^{3}$ College of Harbour, Coastal and Offshore Engineering, Hohai University, Xikang road \#1, 210098, \\ Nanjing, China.
}

\begin{abstract}
This paper presents preliminary results from laboratory experiments which were specifically designed to determine the flow resistance over a water-worked gravel-bed and its impermeable counterpart (cast-bed). The technique used to create the cast-bed is introduced, followed by the description of the experimental setup and the procedure to quantify flow resistance over both the water-worked and cast-bed. The influence of the grain orientation on flow resistance was investigated in an additional set of experiments by rotating the cast-bed through $180^{\circ}$ in the flume. The main focus of the paper is on the comparison of the bulk flow characteristics for the three different cases for which the beds are characterized not only by the same characteristic grain-diameter but also by an identical surface structure. The obtained results show that the porous, non-porous bed and rotated bed result in different flow resistance and that both bed porosity and grainorientation have a significant effect on flow resistance.
\end{abstract}

\section{Introduction}

The quantification of flow resistance of rivers and stream rivers is of fundamental importance for fluvial geomorphology, river hydraulics, and ecology since it determines flow properties such as mean flow velocity, turbulence, and sediment transport as well as habitat conditions. Traditionally, the roughness of gravel-bed rivers has been associated with a characteristic grain size of the bed material (e.g., $\mathrm{d}_{50}, \mathrm{~d}_{84}$, or $\mathrm{d}_{90}$ ) and flow resistance is parametrized by 'roughness coefficients' or 'friction factors' such as Manning's $n$, Chezy's $C$ and DarcyWeisbach's $f$ [e.g., 1-5]. All existing approaches have in common that the structure of the subsurface layer is not specifically taken into account; in fact, it is often tacitly assumed that porous and non-porous beds are characterized by the same flow resistance given that their surface geometry is identical. However, river beds with a porous sub-surface are characterized by mass and momentum exchange occurring across the sediment-water interface due to the pressure gradients that drive the flow into and out of the bed [6-8]; this

* Corresponding author: christy.ushanth.navaratnam@,ntnu.no 
exchange may affect the hydraulic resistance. Some studies showed that porous beds impose higher flow resistance than their non-porous counterpart for the same flow conditions [e.g., 9-12] and that the friction factors depend on the Reynolds number for a given relative submergence [13]. These studies were mainly based on investigations with artificial beds composed of, for example, single and multiple layers of spheres to mimic a non-porous and porous bed, respectively. On the other hand, a recent study [14] was using a casting technique to reproduce the non-porous counterpart of a gravel-bed surface and indicated that the nonporous cast imposed higher flow resistance than its porous counterpart.

To further explore these aforementioned issues, this paper presents preliminary results from experiments that were specifically designed to study the influence of the sub-surface porosity on flow resistance in gravel-bed rivers. Section 2 describes the preparation of the permeable and non-permeable test surfaces and the experimental program. The results of the measurements are presented and discussed in Section 3. The paper is concluded with a summary of the main findings and an outlook to future research in this field.

\section{Methodology}

\subsection{Preparation of gravel and cast surfaces}

Experiments were carried out in a $12.5 \mathrm{~m}$ long, $1 \mathrm{~m}$ wide and $1 \mathrm{~m}$ deep tilting flume at the hydraulics laboratory at the Norwegian University of Science and Technology (NTNU) Trondheim, Norway. In a first step, a $0.2 \mathrm{~m}$ high layer consisting of well-mixed gravel mixture, with the grain size distribution as shown in Figure 1, was screeded at a length of $10.61 \mathrm{~m}$. In the next step, a stable armor layer was produced by water-working the bed with a steady discharge of $0.2 \mathrm{~m}^{3} / \mathrm{s}$ and quasi-uniform flow conditions (the water surface slope equaled the bed slope of $S=0.0027$ ). Following the creation of the static armor layer, porosity measurements were performed using the water displacement method [see 15,16 for details] to determine the vertical distribution of the porosity of the gravel-bed, which was in average $\phi=0.31$.

Following the hydraulic measurements, which are described in detail in the next section, an impermeable facsimile of a $7 \mathrm{~m}$ long section of the water-worked gravel was produced using the bed casting technique described in $[17,18]$. The bed reproduction technique consisted of two steps; silicon moulding and casting of the non-porous surface using a synthetic resin. Since it was not possible to cast the $7 \mathrm{~m}$ long section in one piece, four smaller sized casts had to be produced (lengths of 1.2 and $2.3 \mathrm{~m}$, two pieces each). Due to their weight, the cast pieces were placed in the flume with the help of a crane. We note that the upstream section of the $10.61 \mathrm{~m}$ long gravel-bed which was not reproduced was replaced by a copy of the cast forming the middle section of the flume surface. Both the gravel and castbeds were scanned using an Acuity AR200-100 laser measurement sensor to obtain digital elevation models (DEMs) of the surfaces. The resolution of the scanned data was $0.3 \mathrm{~mm} \mathrm{x}$ $1 \mathrm{~mm}$ (longitudinal $\mathrm{x}$ transverse directions). The DEMs were used to assess the accuracy of the casting technique and to verify how accurate the cast tiles were placed with respect to the original gravel surface (see below).

The use of the casts also allowed for an additional investigation regarding the effect of grain orientation on the flow resistance. For this purpose, each cast tile was rotated through 180 degrees after the measurements over the initially placed cast surface. Thus, hydraulic measurements were carried out over three different surfaces types: i) water-worked gravelbed, ii) impermeable cast-bed and iii) impermeable rotated cast-bed. Figure 2 shows photos of the water-worked gravel surface and its non-porous cast surface and Table 1 presents the geometrical properties of the three surfaces in terms of the mean bed elevation (from the 
flume bottom), the standard deviation of the bed elevations as well as skewness and kurtosis. The presented values, especially the mean value and the standard deviation, show that the water worked bed could be well reproduced by the cast. The observed minor differences in the statistical parameters for the different bed-types can be associated with the placing of the cast-tiles and the reproduction technique.

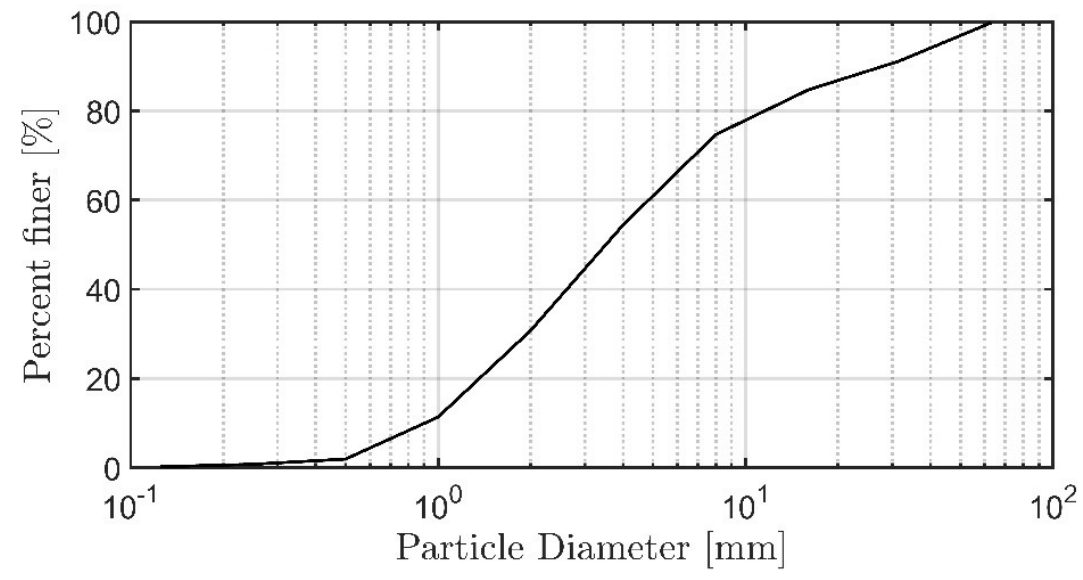

Fig. 1. Grain size distribution of the gravel-mixture
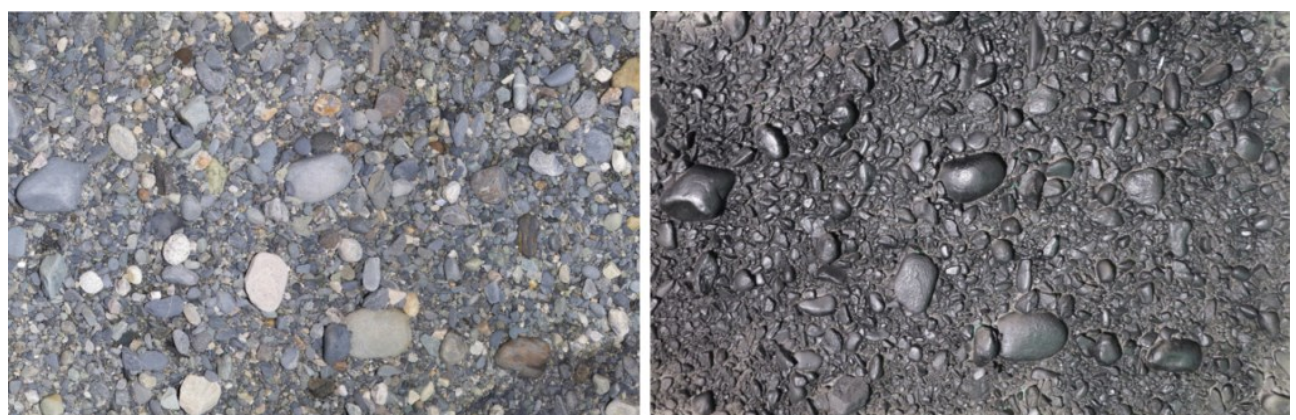

Fig. 2. Left: Water-worked gravel surface, Right: Non-porous counterpart of gravel (cast)

Table 1. Statistical details of the bed surfaces

\begin{tabular}{|l|c|c|c|c|}
\hline Bed Surface & $\begin{array}{c}\text { Mean (from flume } \\
\text { bottom) }[\mathbf{m m}]\end{array}$ & $\begin{array}{c}\text { Standard Deviation } \\
{[\mathbf{m m}]}\end{array}$ & Skewness & Kurtosis \\
\hline Gravel & 182.0 & 7.6 & 0.76 & 1.03 \\
\hline Cast & 182.1 & 8.0 & 0.50 & 0.66 \\
\hline Cast180 (Rotated Cast) & 180.5 & 8.5 & 0.56 & 0.49 \\
\hline
\end{tabular}

\subsection{Hydraulic Measurements}

Hydraulic measurements over the three bed types were carried out for seven different hydraulic boundary conditions (BCs) which are summarised in Table 2. The discharge was measured using inductive flow meters mounted on the recirculation pipes in the flume. In the experiments with the gravel-bed, water surface slopes and water depths were determined with 
four static pressure tubes located at the flume bottom. For the cast measurements, the pressure tubes could not be used as the subsurface was sealed off. Instead, 8 ultrasonic sensors were used to measure the water surface elevations and water surface slope. From these measurements, the mean water depth was determined using the mean bed elevation as datum. Additional tests carried out with the two measurement systems (not shown here) showed that both gave the same water depth and water surface slope so that the results from the experiments carried out over the different surfaces are directly comparable. Although care was taken to carry out the measurements with uniform flow conditions, it was difficult to exactly match the bed slope with the water surface slope. To account for the differences between the bed and water surface slope, the St. Venant equation for non-uniform flow was used to determine the friction velocity [19]:

$$
u_{*}=\left[g h S_{b}+\left(-g h \frac{\partial h}{\partial x}\right)\left(1-F r^{2}\right)\right]^{1 / 2}
$$

where, $u_{*}$ is the friction velocity, $g$ is the gravitational acceleration, $h$, the water depth, $S_{b}$ is the bed slope, $\partial h / \partial x$ is the water depth variation in longitudinal direction and $F r$ is the Froude number. Equation 1 can be simplified for small slopes as in the present experiments:

$$
u_{*}=\left[g h S_{b}-g h\left(S_{b}-S_{w}\right)\left(1-F r^{2}\right)\right]^{1 / 2}
$$

where, $S_{b}$ is the bed slope and $S_{w}$ is the water surface slope. The bulk friction factors were determined using the Darcy-Weisbach friction factor

$$
f=8 \cdot \frac{u_{*}^{2}}{U^{2}}
$$

where the $U$ is the cross-sectionally averaged flow velocity. It should be noted that the relative submergence was kept as constant as possible for each boundary condition and that the discharge was adjusted to achieve the required water surface slope to have comparable conditions.

\begin{tabular}{|c|c|c|c|c|c|c|c|c|c|c|}
\hline$\stackrel{\vec{s}}{\stackrel{\vec{s}}{e}}$ & 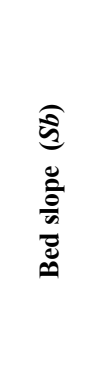 & 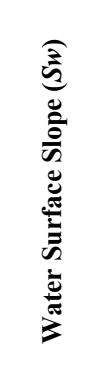 & 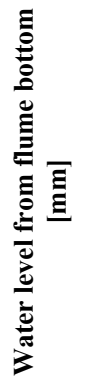 & 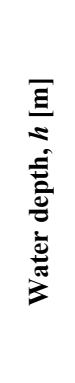 & $\Sigma$ & $\begin{array}{l}\frac{\tilde{a}}{\hat{m}} \\
\stackrel{\Xi}{a}\end{array}$ & $\frac{\bar{n}}{\underline{\Xi}}$ & It & $\approx$ & $\begin{array}{l}\sum_{\Xi}^{n} \\
\stackrel{\Xi}{*}\end{array}$ \\
\hline $\mathrm{BC} 1$ & 0.0018 & 0.00134 & 318.4 & 0.137 & 3.6 & 0.056 & 0.41 & 0.35 & 55890 & 0.043 \\
\hline $\mathrm{BC} 2$ & 0.0015 & 0.00103 & 359.9 & 0.178 & 4.7 & 0.076 & 0.43 & 0.32 & 76270 & 0.043 \\
\hline $\mathrm{BC} 3$ & 0.0015 & 0.00103 & 418.2 & 0.236 & 6.2 & 0.121 & 0.51 & 0.34 & 120787 & 0.050 \\
\hline$\overline{\mathrm{BC} 4}$ & 0.0020 & 0.00159 & 397.1 & 0.215 & 5.7 & 0.124 & 0.58 & 0.40 & 124107 & 0.059 \\
\hline BC5 & 0.0013 & 0.00083 & 474.6 & 0.293 & 7.7 & 0.156 & 0.53 & 0.31 & 156412 & 0.050 \\
\hline BC6 & 0.0010 & 0.00051 & 535.2 & 0.353 & 9.3 & 0.168 & 0.48 & 0.25 & 167987 & 0.043 \\
\hline BC7 & 0.0015 & 0.00098 & $\begin{array}{l}501.3 \\
\end{array}$ & 0.319 & 8.4 & 0.200 & 0.63 & 0.35 & 199823 & 0.057 \\
\hline
\end{tabular}

Table 2. Hydraulic boundary conditions for gravel-bed surface, $k$ is defined as roughness height $(z 99-$ $z_{01}$ ), where $z_{99}$ and $z_{01}$ are $99^{\text {th }}$ and $1^{\text {st }}$ percentile of vertical elevation of the bed surface respectively. 


\section{Results and Discussion}

Figure 3 shows the variations of the bulk friction factor $f$ with the Reynolds-number $R e=U h / v$ for the three bed-types ( $v$ denotes the kinematic viscosity). The figure reveals that the rotated cast exerted higher resistance to the flow than the other two bed surfaces for all boundary conditions except for $R e \approx 170,000$, for which the friction factor of the rotated cast was slightly lower than that of the gravel-bed. This may partly be associated with the uncertainties in the water surface slope measurements for this boundary condition which was characterized by the lowest water surface slope (approx. 0.05\%). The higher flow resistance exerted by the rotated bed shows that the grain orientation has significant influence on the flow resistance and indicates the effectivity of the flow to create a bed imposing less hydraulic roughness (e.g., [20]); the grains for the rotated cast are oriented in the opposite direction compared to the other two surfaces. This result is hence also a strong indicator that the bed roughness cannot be solely described by a characteristic grain diameter and that the surface structure and the orientation of the grains to the flow direction play an important role $[4,5,21]$.

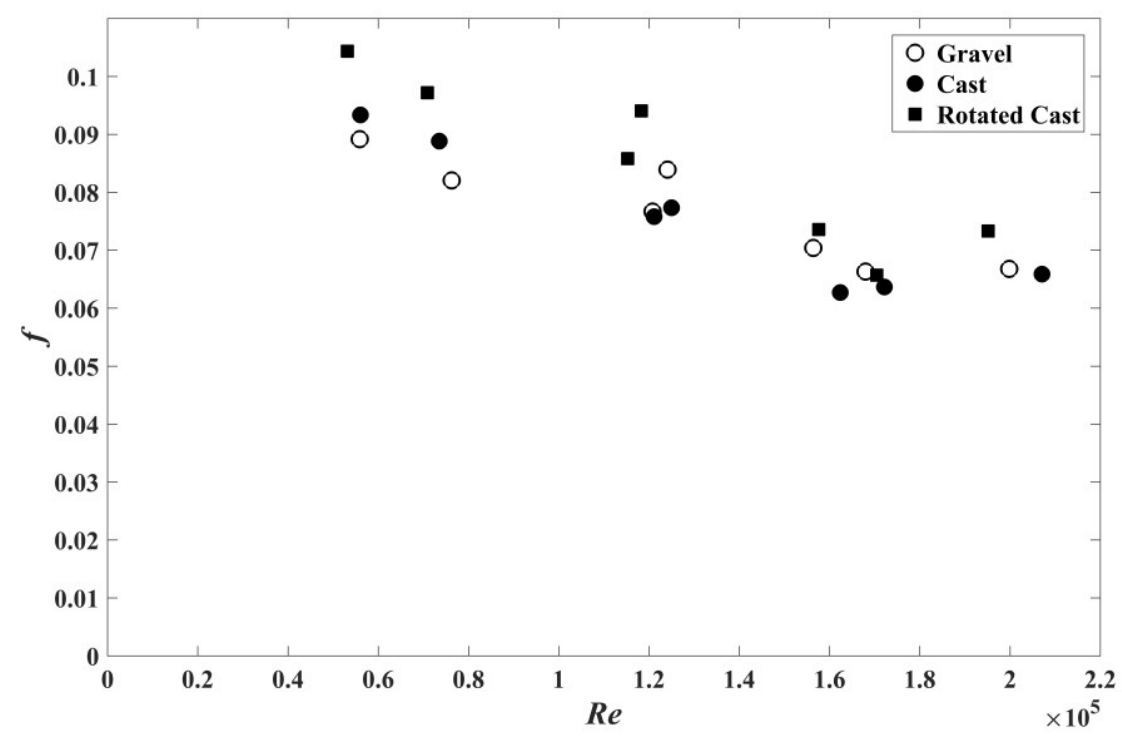

Fig. 3. The variation of bulk friction factors with $R e$, for different surfaces

The water-worked gravel surface exhibited higher flow resistance than the cast surface for $R e>100,000$. However, for the two runs with $R e<100,000$ (i.e. for the lowest discharges used), a lower friction factor was obtained for the water-worked gravel-bed than for the castbed (discussed below). The higher friction over the water-worked gravel-bed can be associated with the momentum transfer in the porous gravel-bed, as the solid bottom of the cast prevents momentum transfer. The effective hydraulic roughness over a porous surface is generally related to the thickness of the interface region [13], i.e. the region of the flow where the surface flow interacts with the porous medium. The interface region is larger for the porous gravel-bed than for the non-porous cast for which it is restricted from the roughness crest to the roughness trough, i.e. in this case it does not include parts of the subsurface layer. Defining the relative submergence as the ratio of water depth to the height of the interface region, the relative submergence will be, for a given water depth, lower for the water-worked gravel-bed than for the cast. This implies a higher friction factor for the flow over the gravel surface compared to the flow over the cast. It should be noted that the 
depth of momentum penetration is limited by the thickness of the porous layer. If the depth of momentum penetration occupies the whole porous layer, the flow resistance can be assumed to be independent of relative submergence.

In order to elaborate this issue further, data from [13] are plotted in Figure 4. The shown friction factors were obtained in experiments over a porous gravel-bed $(f 1)$ and a non-porous gravel-bed $(f)$ (a single layer of gravel grains) for a range of relative submergences. However, the friction factors for the porous and non-porous surfaces were determined in slightly different ways. For the non-porous surface, the datum for the analysis was the flume bottom whereas for porous bed, the datum was located at the roughness top. Thus, the friction factor over the porous bed was slightly underestimated as the relative submergence would be higher compared to the non-porous bed. The level of underestimation is increasing with increasing $R e$ as the depth of momentum penetration is also increasing; as Figure 4 shows, the porous bed imposes higher resistance to the flow than the non-porous bed for a given ratio of water depth to particle diameter $d$. In fact, [13] concluded that the flow resistance in porous beds increases with increasing $R e$ for a given relative submergence. In our study, the relative submergence was kept approximately constant for a given boundary condition enabling the comparison of friction factors between the three-different surfaces, and the higher friction over the water-worked gravel-bed confirms basically the results of [13]. The observed lower friction over the water-worked gravel-bed for the first two boundary conditions may be explained could be associated with the placement of the cast surfaces, because the standard deviation of the bed elevation is slightly higher for the cast than for the gravel which in turn may affect hydraulic roughness, especially for the lowest discharges. On the other hand, the differences in $f$ may also be related to the fact that the subsurface flow rate for the porousbed test was not explicitly measured; i.e. it was not accounted for in the calculation of the bulk-parameters. Preliminary test-computations showed that, considering a subsurface flow rate of 2 1/s, larger $f$-values would be obtained for the porous bed than for the cast-bed.

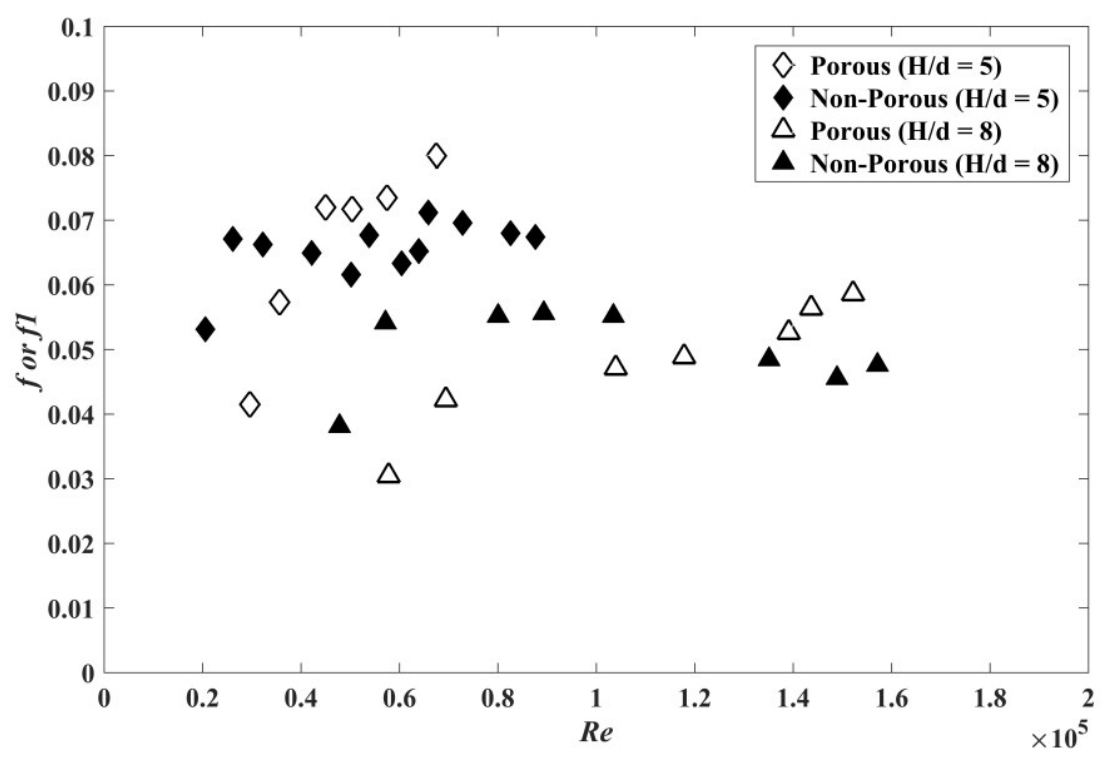

Fig. 4. The variation of friction factors with $R e$, obtained from [13]

The results of the presented experiments were also compared to the results of the recent study of [14], which was based on a similar experimental method. In this study, it was found 
that the bulk flow resistance exerted by a non-porous cast section was higher than the flow resistance exerted by the porous gravel-bed which is not in agreement with the finding of this study (except for two BCs) as well as the aforementioned studies. A possible explanation for this deviation may be that only a small gravel-bed surface section was reproduced in the study of [14] which corresponded to about $5 \%$ of the total water-worked gravel-bed area. In other words, a small section of a cast tile was placed in the middle of a long porous gravel-bed section. As far as the bulk flow resistance is concerned, a larger section of porous gravel-bed $(\approx 95 \%)$ interacts thus with the flow. In contrast to the experiments carried out by [14], the experiments presented in this paper were carried out over a complete non-porous cast-bed and ensured that there was no flow under the cast by sealing off the gaps and joints of the cast tiles. Moreover, about $70 \%$ of the water-worked gravel-bed surface was reproduced in this study and accuracy was verified as reported in the previous section.

\section{Conclusion}

This paper presented preliminary results from an investigation focusing on the bulk flow resistance of three different surfaces; porous water-worked gravel, non-porous facsimiles of gravel (cast) and rotated cast (each cast piece was rotated through 180 degrees). It was shown that the porous gravel-bed exerts higher flow resistance on the flow than its non-porous facsimiles. This was due to the momentum penetration in the porous bed which is dependent on $R e$ for a given relative submergence. A practical implication of this result is that the colmation process (the settling of fine particles in the hyporheic zone), may change the porosity of the sub-surface, and hence flow resistance, or vise versa. The results also revealed that the rotated cast imposed higher friction on the flow than the other two surfaces which demonstrates that grain orientation has significant influence on flow resistance. Thus, it can be concluded that a complete description of gravel-bed roughness requires not only information on the surface structure and on the grain-size distribution of the surface layer, but also information on the sub-surface layer. This issue will be in the focus of our subsequent analyses using flow velocity data acquired with Particle Image Velocimetry over the different beds.

The authors thank Dr. Costantino Manes for providing the data from his study which helped to discuss the findings in this paper.

\section{References}

1. R. D. Hey, J. Hydr. Div., 105, 365-379, (1979)

2. J.C. Bathurst, J. Hydr. Eng., 111, 625-643, (1985)

3. V.I. Nikora, D.G. Goring, B.J.F. Biggs, Wat. Res. Res., 34, 517-527, (1998)

4. J. Aberle, G.M. Smart, J. Hydr. Res., 41, 259-269, (2003)

5. D.M. Powell, Eart. Scie. Rev.,136, 301-338, (2014)

6. D. Tonina, J.M. Buffington, Wat. Res. Res, 43, W01421 (2007)

7. F. Boano, J.W. Harvey, A. Marion, A.I. Packman, R. Revelli, L. Ridolfi, A. Wörman, Revi. of Geop, 52, 603-679, (2014)

8. A. Marion, V. Nikora, S. Puijalon, T. Bouma, K. Koll, F. Ballio, S.Tait, , M. Zaramella, A. Sukhodolov, M. O'Hare, G. Wharton, J. Aberle, M. Tregnaghi,, P. Davies, H. Nepf, G. Parker, B. Statzner, J. Hydr. Res., 52, 744-758, (2014)

9. A.F.E. Zagni, K.V.H. Smith, J. Hydr. Div., 102, 207, (1976) 
10. H.J.Zippe, W.H.Graf, J. Hydr. Res., 21, 51-65, (1983)

11. W.P. Breugem, B. J. Boersma, R.E. Uittenbogaard, J. Flui. Mech., 562, 35-72, (2006)

12. C. Manes, D. Pokrajac, I. McEwan, V.I. Nikora, Phys. of Flui., 21, 125109 (2009)

13. C. Manes, D. Pokrajac, V.I. Nikora, L. Ridolfi, D. Poggi, Geop. Res. Let, 38, L03402, (2011)

14. J.R. Cooper, A. Ockleford, S.P. Rice, D.M. Powell, Eart. Surf. Proc. Land., (In press)

15. J. Aberle, Acta Geop. 55, 23-32, (2007)

16. C.U. Navaratnam, J. Aberle, J. Daxnerová, in: Free Surface Flows and Transport Processes (Springer, 2018)

17. S. Spiller, N. Rüther, 2nd IAHR Europe Conference (Munich, Germany, 2012)

18. C.U. Navaratnam, J. Aberle, S.M. Spiller, in : River Flow 2016 (CRC Press, Taylor \& Francis Group, 2016)

19. W.H. Graf, T. Song, J. Hydr. Res., 33, 699-704, (1995)

20. L.B. Leopold, W.B. Langbein, in: Theoretical papers in the hydrologic and geomorphic sciences, (U.S. Govt. Print. Off, 1962)

21. K.A. Flack, M.P. Schultz, J. of Fluids Eng., 132, 041203-041203-10, (2010) 